Journal of Electrical Engineering and Automation (EEA) (2020)

Vol.02/ No. 01

Pages: $1-12$

https://www.irojournals.com/iroeea

DOI: https://doi.org/10.36548/jeea.2020.1.001

\title{
Smart Wireless sensors for Impairment detection of the offshore Wind Turbines
}

\author{
Dr. G. Ranganathan, \\ Professor, Electronics and Communication Engineering, \\ Gnanamani College of Technology, \\ Namakkal, India. \\ Email: profranganathang@gmail.com \\ Dr. S. Smys, \\ Professor, Department of Computer Science and Engineering, \\ RVS Technical Campus, \\ Coimbatore, India. \\ Email: $\underline{\text { smys375@gmail.com }}$
}

\begin{abstract}
The maintenance of Wind farms located in the off shores are highly challenging as the preservation and the operational availability are tedious. The insufficiency in the traditional system for monitoring the conditions of the wind turbines located in the off shores has made this topic an attractive area of research. The proposed method in the paper utilizes the multiple intelligent smart sensors to detect the impairments in the structure of the wind turbines. The sensors utilized in the proposed method estimates the damage index in the wind turbine by engaging the embedded software. The effectiveness of the proposed method was measured by applying it to the off shore wind turbines. The results obtained evinces the minimized cost and the down time in maintaining the off shore wind farms.
\end{abstract}

Keywords: Wind Farm Monitoring, impairment detection, on board multi-sensors, embedded software, Enhanced Maintenance

\section{Introduction}

The structural health monitoring is the procedures in detecting the impairments in the mechanical and the electrical equipment's that are related to the applications such as the aerospace, energy convertors etc. following key methodologies to identify the damages. This type health monitoring has been compatible for maintaining the large infrastructures such as bridges, buildings and the wind turbines. This paper mainly 
Journal of Electrical Engineering and Automation (EEA) (2020)

Vol.02/ No. 01

Pages: $1-12$

https://www.irojournals.com/iroeea

DOI: https://doi.org/10.36548/jeea.2020.1.001

concentrates on the off shore wind turbine maintenance as the off shore wind turbines does not have much accessibility especially when the weather conditions are too bad or when high production rate is experience due to the heavy strong winds.

Increasing number of wind power plants on the offshore areas demands good maintenance to extend the life span of the power plants. The conventional methods followed procedures such as the reactive maintenance to run the plant until the failures occurred. The maintenance followed in the early stages was segregated into two stages as preventive and corrective in which the preventive measures were further divided as the scheduled and condition based, this was done to prevent the failures and he later was carried out to correct the failures occurred. But the corrective and the preventive measures for an offshore wind turbine is very challenging due to their less accessibility. Despite the capabilities of the off shore power plants to generate high energy as it is equipped with the very high wind resources and large space, the maintenance of the plant is costly as it is placed very far from the land. The cost of maintaining the offshore power plant accounts at least $30 \%$ to $35 \%$ of the average cost required to produce electricity form the wind power plant. The main scope of the paper is to minimize the total maintenance cost of the off shore wind turbines by utilizing the smart sensors.

The wind turbine in the off shores needs well planned operations and maintenance to warrant the system is cost effective, harmless and profitable. To provide early as well as timely recovery for the impairments in the offshore wind turbines, the proposed method in the paper utilizes the sensor technology to monitor the severity of the impairments in the wind structures, by identifying the changes in the structural behaviors. The figure. 1 below shows the essential constituents of the off shore wind turbine.

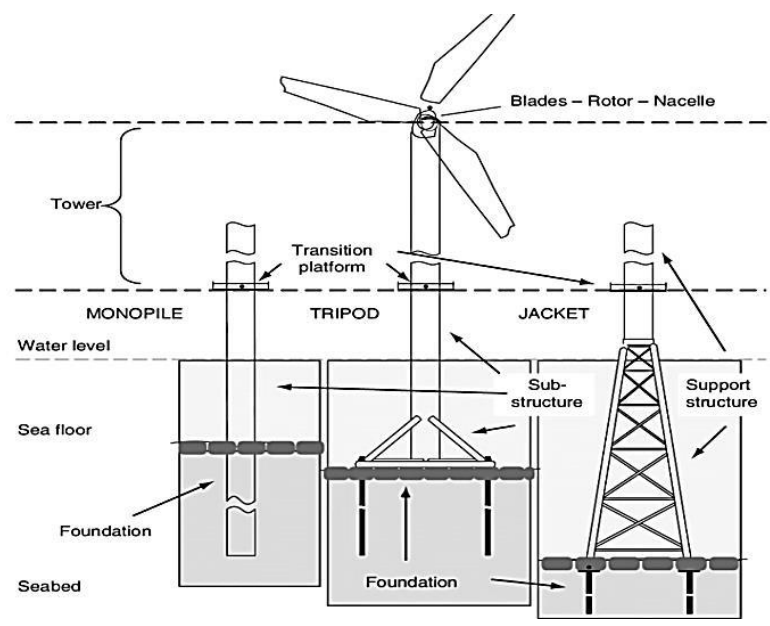

Figure.1 Offshore Wind Turbine System 
Journal of Electrical Engineering and Automation (EEA) (2020)

Vol.02/ No. 01

Pages: $1-12$

https://www.irojournals.com/iroeea

DOI: https://doi.org/10.36548/jeea.2020.1.001

The paper utilizing the sensor technology in monitoring the health status of the off shore wind turbine, is arranged with the section 2 providing the survey on conventional methods in monitoring the health status of the wind turbines-offshore and the capabilities of the sensor technology, the section 3. Proposing the utilization of multiple sensors in monitoring the heath conditions of the wind turbines, section 4 validates the performance of the proposed method by applying it to an offshore wind turbine and section 5 provides the conclusion.

\section{Literature survey}

The literature survey of the paper explains both damages caused in the wind turbines, the conventional methods used in detecting it and the description of the smart sensor that their capabilities in monitoring even the slight changes in the environment.

The author Rolfes, R., W et al [1] in his paper has put forth the method of damage detection in the identifying the impairments in the rotor blades and the Tower of the wind turbines-offshore investigating the basic theory on the "proportionality of the maximum dynamic stress and velocity"

Friedmann, et al [2] the paper applies a combination of different monitoring strategies to detect the health status of the wind turbines that are located onshore, the paper employs different types of wireless sensors to acquire the data and reduce the efforts of cabling for information transfer and analyses the data acquired to gain insights about its health status of WT, though the method seems to be cost effective the reliability in data transmission is still questionable.

Ciang et al [3] the author elaborates the few conventional methods of damage detection applied to the wind turbine system. such as the the "Acoustics emission events detection method, thermal imaging method, ultrasonic method, model based approaches, fiber optics, electrical resistance, laser Doppler, X-ray method, strain memory alloy, eddy current", etc.

Amirat, Yassine, et al [4] the paper provides the significance of performing the condition monitoring and the fault diagnosis in the WECS and provides a brief status explaining various types of faults the signatures generated by them and the conventional strategies used in diagnosing the faults. Di Lorenzo, et al [5] the method put forth utilizes the "operational modal analysis" for the HA type wind turbines, but works without taking into consideration the periodicity of the structure increasing the complexity in operations of the wind turbines. 
Journal of Electrical Engineering and Automation (EEA) (2020)

Vol.02/ No. 01

Pages: $1-12$

https://www.irojournals.com/iroeea

DOI: https://doi.org/10.36548/jeea.2020.1.001

Kabir, M. J et al [6] as the monitoring of the conditions and the diagnosing of the faults take an important part in the enhancing the lifetime of the offshore wind turbines and also minimizing the maintenance as well as the operational cost. The paper elaborates the predictive heath monitoring system to elude the break down and the machine down time, by presenting the review on the various conditional monitoring techniques available taking into consideration the majority of the faults occurring in the bearing, gear box, blade and the rotor, pitch, tower system and the yaw, as well in controlling and the generating system.

Hoell et al [7] the method put forth in the paper detects the damages in the blades of the wind turbines utilizing the time series methods. Fritzen et al [8] the paper puts forth the "integrated structural health monitoring using the off shore wind energy plants using the sensors" Yang et al [9] propose the "way to cost effectively monitor the failures and the faults in the wind turbines". Swartz et al [10] proposes the method of monitoring the faults in the wind turbines using the wireless sensor networks. But the single sensors engaged to perform the SHM on the structures of the wind turbine is a failure due to the reliability and accuracy of the methods are questionable. Wymore et al [11] "is the survey on the health monitoring for the wind turbines. The papers Duraipandian, M., et al [12], Wang, H. et al [13], Kumar et al [14] and Valanarasu, et al [15] provides the essentiality of the sensors in the monitoring the changes in the surroundings and their vital role in the internet of things. The incompetence of the single sensors engaged monitoring is over come in the paper using multiple sensors. The proposed method in the paper utilizes the multi sensors technology to detect the damages in the structure of the offshore wind turbines by estimating the damage index and severity in the damages utilizing the accelerometer and the gyroscope's

\section{Proposed Model}

The proposed model is made possible by the advancements in the micro electro mechanical systems that have paved way for the development of the smart sensors that are based on the techniques of the MEMS. These sensors are enabled with the multiple and sovereign data acquisitions capabilities making probable the multiple wireless sensors to be deployed at the remote location at a reduced cost and are found to be compatible even for the off shore wind turbines monitoring. The installation and the maintenance of the system are easily done in a cost effective manner.

Smart wireless sensor infrastructure with the on board data computation, incorporating, the hard wares for the acquiring the data using the multi sensor, embedded with the software to estimate the damage index and the damage severity. The flow diagram below in figure .2 proposed smart sensor technology based off shore wind turbine monitoring. 
Journal of Electrical Engineering and Automation (EEA) (2020)

Vol.02/ No. 01

Pages: $1-12$

https://www.irojournals.com/iroeea

DOI: https://doi.org/10.36548/jeea.2020.1.001

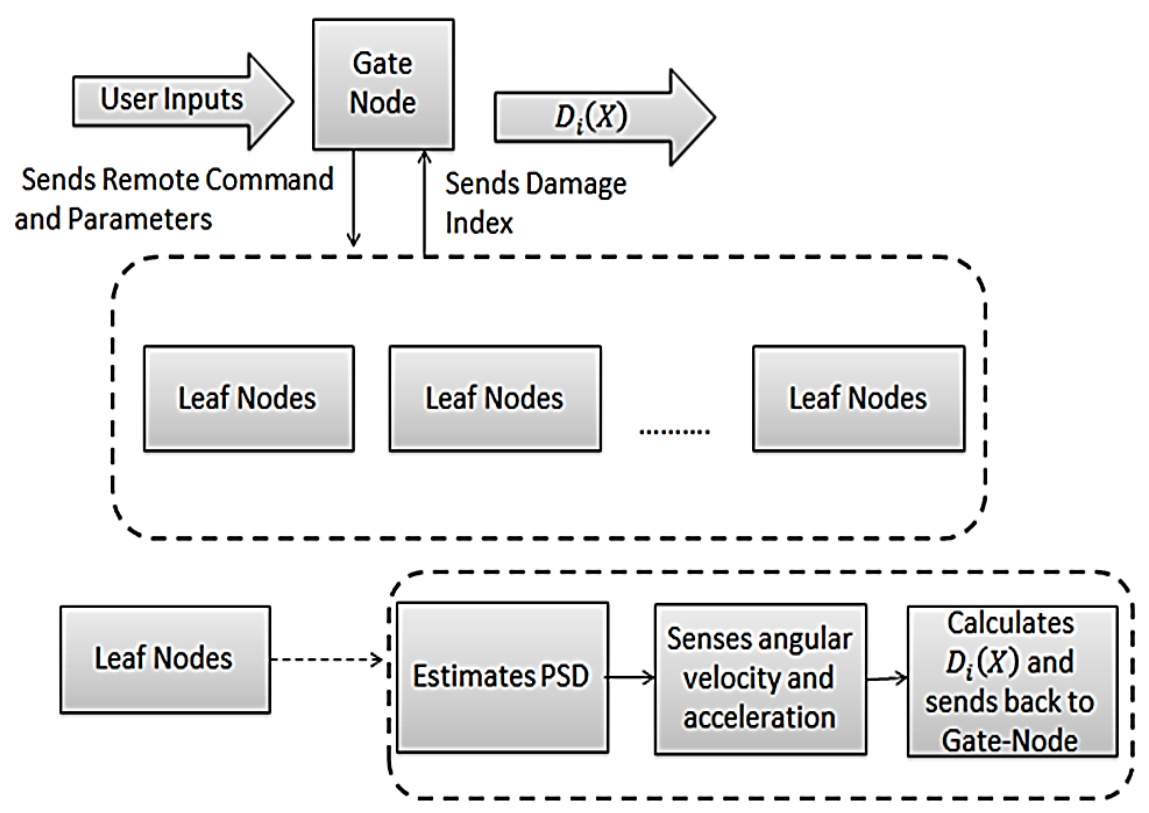

Figure.2 Proposed Flow diagram

\subsection{The Hardware Used}

The proposed method in the paper utilizes the I mote 2 (MEMSIC) to create a smart wireless sensor network with the capability to identify the defects in the wind turbines observing the damage index. The board holds enough computing capabilities, and is enriched with large memories, the reliability of the hardware and the software used is very high [13], the ISM 400 sensor to sense the variation in the acceleration's and the ADXRS623 analog devices (gyroscope) to sense the angular velocity. The utilization of the smart sensors ensures continuous data collection and warns the ascend of abnormal conditions.

\subsection{Mote2 Sensors (MEMSIC)}

The wireless sensor platform developed using the MEMSIC's I Mote 2 sensors is capable of providing a heightened data-throughput for its applications in monitoring health. The Imote2's has a powerful processing capabilities and constitutes an on board memory ( $256 \mathrm{~KB}$ of integrated RAM, $32 \mathrm{MB}$ of external SD-RAM and Flash Memory) to perform a high-frequency sampling that is entailed in the structural- 
Journal of Electrical Engineering and Automation (EEA) (2020)

Vol.02/ No. 01

Pages: $1-12$

https://www.irojournals.com/iroeea

DOI: https://doi.org/10.36548/jeea.2020.1.001

monitoring. The power consumption is very much optimized as the processor engaged is a low power (marvel $\mathrm{x}$-scale) processor with a capacity to operate at varying processing speed. The I mote sensor platform is shown in the figure. 3 below.

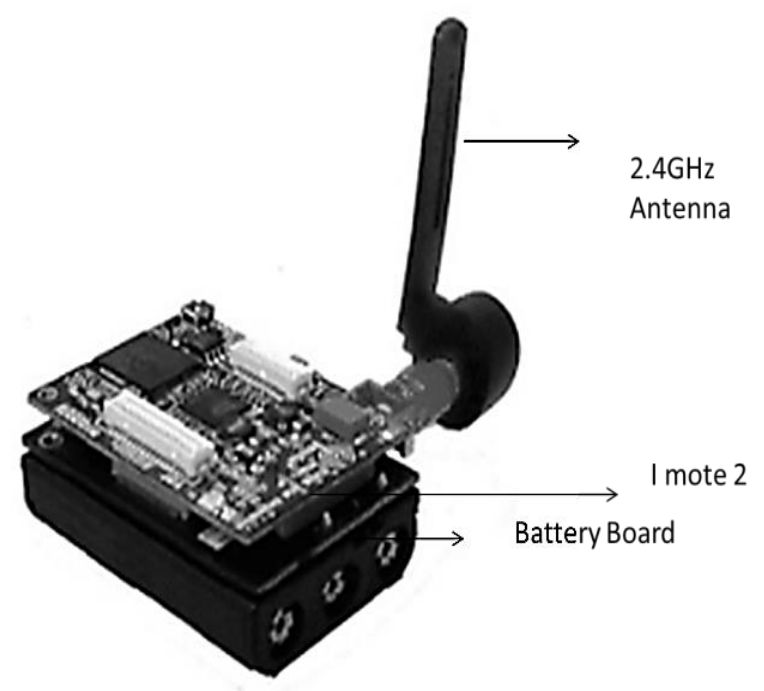

Figure.3 I Mote 2 sensor platform

\subsection{SHM- Accelerometer Sensor Board (ISM400)}

The accelerator sensor board with the structural monitoring capabilities was basically designed to meet the precise demands of the structural monitoring in the, board is enriched to provide flexible as well as accurate sampling rates along with the competence of anti-aliasing filtering to identify the behavior of the structural damages. The sensor board is equipped with the general analog input, and three axis accelerometer that is analog to measuring the vibrations and also holds, temperature sensor that is digital to deliver the onboard temperature reparation to the acceleration information and further has a light and humidity sensors also. The SHM- accelerometer sensor board is interfaced with the I mote through the I2C and SPI I/O pins. This greatly reduces the complexity and the time consumption in the development of the Structural health monitoring. The figure.4 below is the SHM- Accelerometer Sensor board. 
Journal of Electrical Engineering and Automation (EEA) (2020)

Vol.02/ No. 01

Pages: $1-12$

https://www.irojournals.com/iroeea

DOI: https://doi.org/10.36548/jeea.2020.1.001

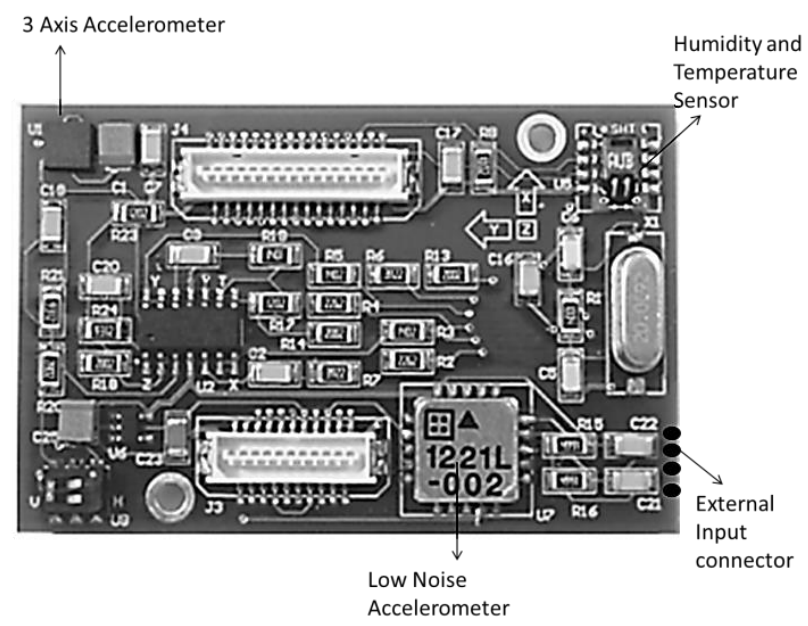

Figure .4 SHM - Acceleration Sensor Board

\subsection{Angular Rate Sensor (ADXRS623)}

The Angular rate sensor, ADXR623 (Gyroscope) is used to amount the responses obtained from the z-axis at a measuring range of \pm 250 degree/seconds and low bias drift of 12 degree/hour. The figure. 8 below is the angular rate sensor. The gyroscope is mounted on the I mote sensor measures the angular velocity and plays a vital role in estimating the power spectral density and evaluating the structural damages according to the developed damage index.

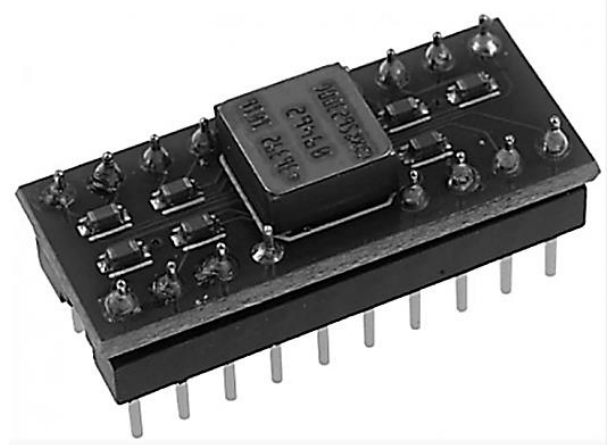

Figure. 5 ADXR623- Angular Rate Sensor 
Journal of Electrical Engineering and Automation (EEA) (2020)

Vol.02/ No. 01

Pages: $1-12$

https://www.irojournals.com/iroeea

DOI: https://doi.org/10.36548/jeea.2020.1.001

\subsection{Methodology}

An open source software package tool suite of ISHMP based on the I mote was used to feed the developed damage index into the smart sensor platform. The wireless platform had base stations to convey the user inputs to the gateway-node and to receive the processed data's after the completion of the process. The gate-node is used to regulate the sensor networks that are present in the leaf-nodes whereas the leaf-nodes holds the functions that are required in measuring the responses such as the angular velocity, acceleration etc. on receiving the initial user input the complete sensor paradigm does a network-wide time synchronization and parallely does the data question using the multi-sensors. The synchronization increases the availability of data and the leaf-node starts to estimate the power spectral density prior to the evaluation of the damage index. The damage index $\left(D_{i}(X)\right)$ is estimated as shown in the equation (1) below.

$$
D_{i}(X)=\frac{\operatorname{Ang}_{v e l(i)}(X)}{A C C_{i}(X)}
$$

Where the $A n g_{v e l(i)}(X)$ is the angular velocity of the variation for ' $\mathrm{t}^{\text {th' }}$ frequency and the $A C C_{i}(X)$ is the acceleration variations on the same frequency at the position $X$. The change in the acceleration and the angular velocity are measured employing the sensors to identify the alterations in the boundary conditions and as well as the changes in the amplitude response. The $D_{i}(X)$ is acquired from the angular velocities and the accelerations power spectral density (PSD) as shown below in the equation (2)

$$
D_{i}(X)=\sqrt{\frac{P S D_{a n}\left(\propto_{i} X\right)}{P S D_{a c c}\left(\alpha_{i} X\right)}}
$$

Where the $P S D_{a n}$ - angular velocities PSD and the $P S D_{a c c^{-}}$is the acceleration PSD, $\propto_{i}$, is the natural frequency and the normalized $D_{i}(X)$ is obtained using the equation (3).

$$
\operatorname{Norm}_{i}(X)=\frac{1}{P Q} \sum_{x=1}^{p} \sum_{y=1}^{q}\left|\frac{D_{i, \operatorname{damage}}(X)}{D_{i}, \text { undamage }(X)}-1\right|
$$

The 'p' and ' $q$ ' are the counts of the frequencies used and the nodes used. The proposed method is widely used in measuring the defects in the bottom of the monopile structure in the wind turbines. At the final stage the gate-node obtains the $D_{i}(X)$ estimated by every single wireless sensor. The figure. 6 . Details the particulars of the numerical algorithms provided by the ISHMP tool suite to implement the structural health monitoring applications over I mote 2. 
Journal of Electrical Engineering and Automation (EEA) (2020)

Vol.02/ No. 01

Pages: $1-12$

https://www.irojournals.com/iroeea

DOI: https://doi.org/10.36548/jeea.2020.1.001

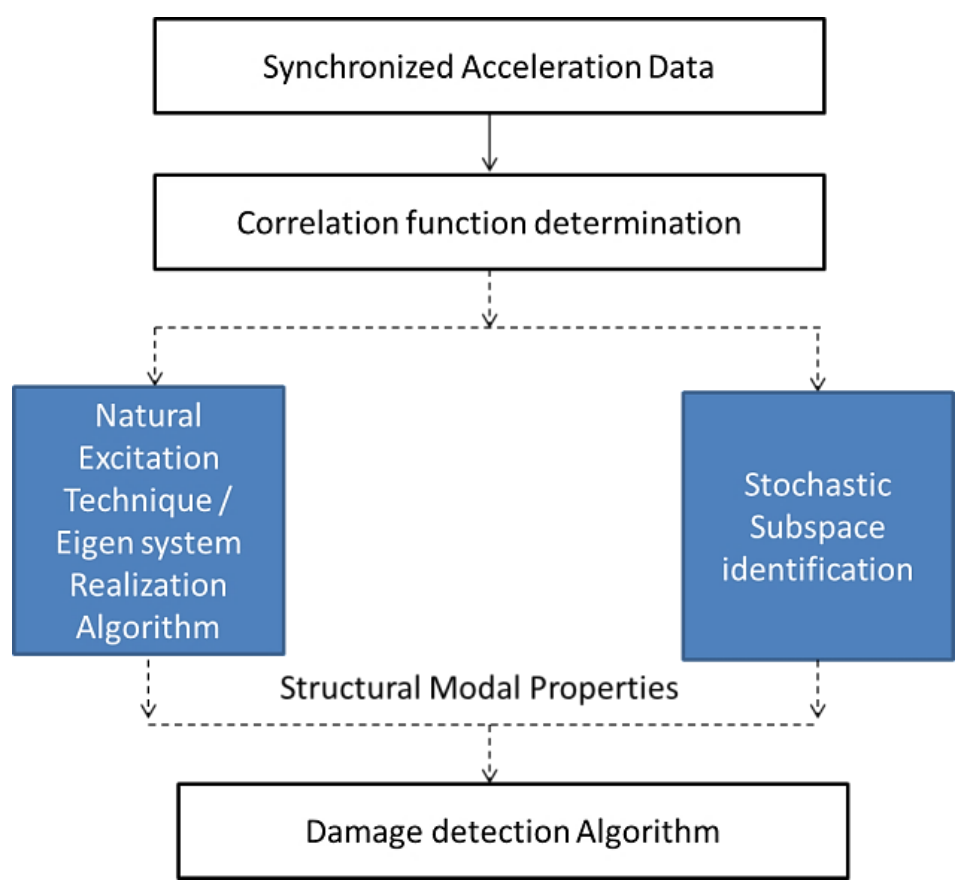

Figure.6 Numerical Algorithms Provided by the ISHMP Tool-suite

\section{Result Analysis}

The multi-sensor technology is employed over an offshore power plant found off the coast of Tamil Nadu to validate its performance the damage and the undamaged cases were observed for 5 different modes with accurate damage severity estimations. The Table.1 below provides the damage cases and the intact cases observed in the offshore power plants. 
Journal of Electrical Engineering and Automation (EEA) (2020)

Vol.02/ No. 01

Pages: $1-12$

https://www.irojournals.com/iroeea

DOI: https://doi.org/10.36548/jeea.2020.1.001

\begin{tabular}{|l|l|l|l|l|l|}
\hline Cases & $\begin{array}{l}\text { First } \\
\text { Mode }\end{array}$ & $\begin{array}{l}\text { Second } \\
\text { Mode }\end{array}$ & $\begin{array}{l}\text { Third } \\
\text { Mode }\end{array}$ & $\begin{array}{l}\text { Fourth } \\
\text { Mode }\end{array}$ & $\begin{array}{l}\text { Fifth } \\
\text { Mode }\end{array}$ \\
\hline $\begin{array}{l}\text { Damage } \\
\text { Case 1 }\end{array}$ & -.492 & -.501 & -.65 & -.873 & -1.2 \\
\hline $\begin{array}{l}\text { Damage } \\
\text { Case 2 }\end{array}$ & -.567 & -.674 & -.746 & -.543 & -.546 \\
\hline $\begin{array}{l}\text { Damage } \\
\text { Case 3 }\end{array}$ & -1.07 & -.1 .56 & -.1 .80 & -.889 & -.678 \\
\hline $\begin{array}{l}\text { Undamaged } \\
\text { Case }\end{array}$ & 0 & 0 & 0 & 0 & 0 \\
\hline
\end{tabular}

Table.1 Damage and Undamaged Case

The experiment cases are elaborated in the fig .7 and fig .8 below; the description provided describes the damage conditions observed under each case. The figure. 8 compares the accuracy of the damage detection by the proposed method and the conventional methods that were gone through in the literature survey.

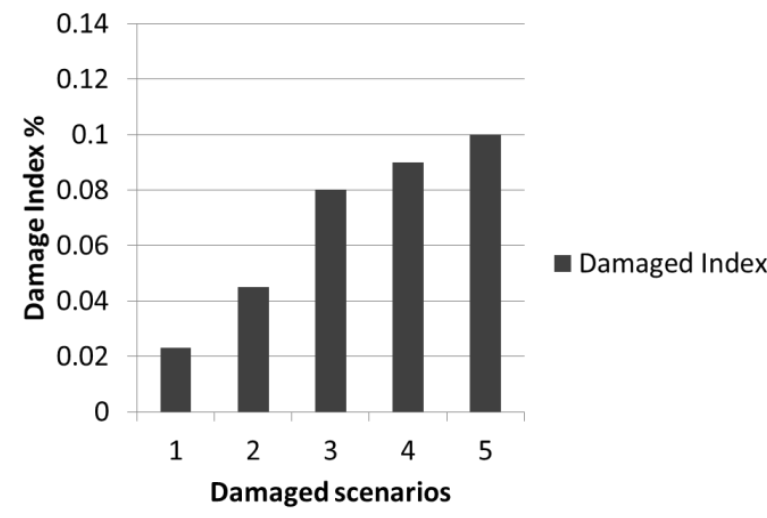

Figure .7 observed damage index

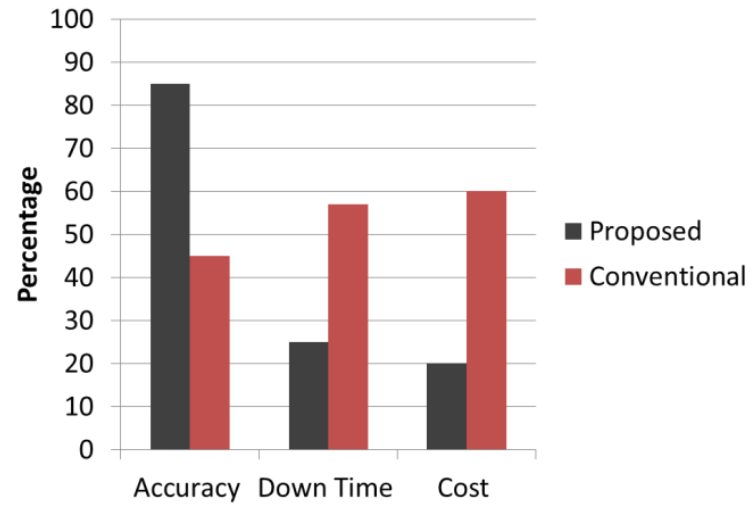

Figure.8 Performance Observed

The figure .7 observed damage cases under five different circumstances, in which certain cases showed only single damage whereas certain showed more than one damages the percentage of the accumulated damage case is shown in the figure.7. More over the accuracy percentage showed in the figure .8 shows 
Journal of Electrical Engineering and Automation (EEA) (2020)

Vol.02/ No. 01

Pages: $1-12$

https://www.irojournals.com/iroeea

DOI: https://doi.org/10.36548/jeea.2020.1.001

that the proposed model provides accurate damage detection compared to the conventional methods. Through the proposed method the down time of the wind turbines and the cost in maintaining is also very much reduced due to the utilization of the smart sensors in monitoring the behaviors of the wind turbines located off the shore.

\section{Conclusion}

To overcome the difficulties and complexities in detecting the defects in the offshore power plants (wind turbines) the proposed method in the paper utilizes the multi-sensory technology. The multi-sensory technology is made possible BY interfacing the accelerator sensor boards and the angular rate sensors to the I mote sensors platform that is embedded with the detection algorithm. The proposed model utilizes the ISHMP open source tool suite to feed in the damage detection algorithm. The damage detection is experimented over the offshore wind turbines that are mostly off the coasts of Tamil Nadu. The accuracy in detection and the time taken to detect was considerably low when compared to the conventional methods defect detection.

\section{References}

[1] Rolfes, R., W. Gerasch, G. Haake, J. Reetz, and S. Zerbst. "Early damage detection system for towers and rotor blades of offshore wind turbines." In Third European Workshop on Structural Health monitoring, Granada, Spain, pp. 455-462. 2006.

[2] Friedmann, Andreas, Dirk Mayer, Michael Koch, and Thomas Siebel. "Monitoring and damage detection in structural parts of wind turbines." Fundamental and Advanced Topics in Wind Power (2011): 207.

[3] Ciang, Chia Chen, Jung-Ryul Lee, and Hyung-Joon Bang. "Structural health monitoring for a wind turbine system: a review of damage detection methods." Measurement science and technology 19, no. 12 (2008): 122001.

[4] Amirat, Yassine, Mohamed El Hachemi Benbouzid, Elie Al-Ahmar, Bachir Bensaker, and Sylvie Turri. "A brief status on condition monitoring and fault diagnosis in wind energy conversion systems." Renewable and sustainable energy reviews 13, no. 9 (2009): 2629-2636.

[5] Di Lorenzo, Emilio, G. Kosova, U. Musella, S. Manzato, Bart Peeters, F. Marulo, and Wim Desmet. "Structural Health Monitoring challenges on the 10-MW offshore wind turbine model." In Journal of Physics: Conference Series, vol. 628, no. 1, p. 012081. IOP Publishing, 2015.

[6] Kabir, M. J., Amanullah MT Oo, and Mahbub Rabbani. "A brief review on offshore wind turbine fault detection and recent development in condition monitoring based maintenance 
Journal of Electrical Engineering and Automation (EEA) (2020)

Vol.02/ No. 01

Pages: 1-12

https://www.irojournals.com/iroeea

DOI: https://doi.org/10.36548/jeea.2020.1.001

system." In 2015 Australasian Universities Power Engineering Conference (AUPEC), pp. 1-7. IEEE, 2015.

[7] Hoell, Simon, and Piotr Omenzetter. "Damage Detection in a Wind Turbine Blade Based on Time Series Methods." 2014.

[8] Fritzen, Claus-Peter, Peter Kraemer, and Maksim Klinkov. "An integrated SHM approach for offshore wind energy plants." In Structural Dynamics, Volume 3, pp. 727-740. Springer, New York, NY, 2011.

[9] Yang, Wenxian, Peter J. Tavner, Christopher J. Crabtree, and Michael Wilkinson. "Costeffective condition monitoring for wind turbines." IEEE Transactions on industrial electronics 57, no. 1 (2009): 263-271.

[10] Swartz, R. Andrew, Jerome P. Lynch, Stephan Zerbst, Bert Sweetman, and Raimund Rolfes. "Structural monitoring of wind turbines using wireless sensor networks." Smart structures and systems 6, no. 3 (2010): 183-196.

[11] Wymore, Mathew L., Jeremy E. Van Dam, Halil Ceylan, and Daji Qiao. "A survey of health monitoring systems for wind turbines." Renewable and Sustainable Energy Reviews 52 (2015): 976-990.

[12] Duraipandian, M., and R. Vinothkanna Mr. "cloud based internet of things for smart connected objects." Journal of ISMAC 1, no. 02 (2019): 111-119.

[13] Wang, H. (2019). Sustainable development and management in consumer electronics using soft computation. Journal of Soft Computing Paradigm (JSCP), 1(01),56.

[14] Kumar, R. Praveen, and S. Smys. "A novel report on architecture, protocols and applications in Internet of Things (IoT)." In 2018 2nd International Conference on Inventive Systems and control (ICISC), pp. 1156-1161. IEEE, 2018.

[15] Valanarasu, Mr R. "Smart And Secure Iot And Ai Integration Framework For Hospital Environment." Journal of ISMAC 1, no. 03 (2019): 172-179.

[16] Sim, Sung-Han, Jian Li, Hongki Jo, Jong-Woong Park, Soojin Cho, Billie F. Spencer Jr, and Hyung-Jo Jung. "A wireless smart sensor network for automated monitoring of cable tension." Smart Materials and Structures 23, no. 2 (2013): 025006. 